TEIXEIRA, Carla Costa \& CHAVES, Christine Alencar (orgs.). 2004. Espaços e tempos da política. Rio de Janeiro : Relume-Dumará.

\title{
ETNOGRAFIA DOS ESPAÇOS E DOS TEMPOS DA POLÍTICA
}

\author{
John Comerford
}

O livro organizado por Carla Teixeira e Christine Chaves, Espaços e tempos da política, traz alguns dos resultados de trabalhos realizados por pesquisadores do Núcleo de Antropologia da Política (NuAP) vinculado ao Museu Nacional, que surgiu com base em um amplo projeto apoiado pelo Conselho Nacional de Desenvolvimento Científico e Tecnológico (CNPq) de 1997 a 2004, por meio do Programa de Apoio a Núcleos de Excelência (Pronex), e que foi coordenado por Moacir Palmeira (Universidade Federal do Rio de Janeiro (UFRJ)), Mariza Peirano (Universidade de Brasília (UnB)) e César Barreira (Universidade Federal do Ceará (UFC)). Os temas enfocados por cada um dos trabalhos presentes no livro compõem um painel bastante diverso, refletindo a multiplicidade de temas específicos abordados no âmbito do NuAP. Assim, após a apresentação de Teixeira e Chaves, segue-se, na parte I (“Tempos da política”), o trabalho de Antonádia Borges (2004), abordando uma categoria (o “tempo de Brasília”, referindo-se ao tempo de residência de alguém no Distrito Federal), ao mesmo tempo burocrática e de uso corrente, que é chave na construção cotidiana da relação entre governo e moradores do Distrito Federal; o trabalho de Ana Rosato e Julieta Quirós (ROSATO \& QUIRÓS, 2004), comparando concepções e práticas de militância política em dois partidos argentinos (o Partido Justicialista e o Partido Obrero) a partir de uma etnografia das eleições de 2001, em que mostram os diferentes pressupostos quanto à relação entre partido e eleitores e ao modo de construção da liderança dentro do partido, e o trabalho de Irlys Barreira (2004), refletindo a respeito dos usos de emoções e sentimentos na retórica da campanha presidencial de 2002 e os seus efeitos políticos. Na Parte II (“Espaços da política”), Márcia Sprandel (2004) trata da despolitização de discursos acadêmicos e políticos sobre a pobreza, contrastando os atualmente predominantes, que se baseiam na quantificação e em questões vistas como técnicas, com as formulações anteriores, centradas em categorias como "raça", "natureza" e "doença”. Em seguida, Christine Chaves (2004) analisa o Tribunal Internacional dos Crimes do Latifúndio e da Política Governamental de Violação dos Direitos Humanos no Paraná, promovido em Curitiba em 2001 por um amplo espectro de organizações, mostrando como esse evento, cuja forma foi baseada naquela dos tribunais oficialmente constituídos, porém sem ter sustentação na força política do estado, conseguiu mesmo assim realizar efeitos políticos que forçaram o Estado a dar respostas. Carla Teixeira (2004) traz uma etnografia de situações no parlamento que, em termos regimentais, constituiriam quebra do decoro, mas são toleradas, trazendo à tona valores, relações e estratégias fundamentais para a compreensão daquele universo social. Por fim, Marcos Otávio Bezerra (2004) analisa a implementação do orçamento participativo em um bairro de Niterói, mostrando como os efeitos políticos concretos de propostas gerais só podem ser compreendidos partindo-se das relações sociais e das formas políticas previamente estabelecidas - nesse caso, especialmente as modalidades de disputa pelo monopólio da representação política de um determinado bairro.

Conforme apontam as organizadoras em sua apresentação (TEIXEIRA \& CHAVES, 2004), os dois eixos em que o livro está organizado, e que lhe dão o título, não só retomam e reconfiguram a herança de Durkheim e Mauss com relação à constituição social das categorias "tempo" e "espaço", como também se ancoram no trabalho etnográfico tanto dos autores presentes nessa coletânea como do conjunto dos pesquisadores do NuAP. As autoras lembram a importância que teve para a própria definição do projeto de uma Antropologia da Política a compreensão da expressão "tempo da política”, conforme analisada por Palmeira e Heredia em vários artigos, a partir da etnografia de eleições em Pernambuco e no Rio Grande do Sul. Essa análise insere esse "tempo" nas tramas sociais em que ganha sentido e enfoca a relação entre política, temporalização e ordenamento social e cosmológico. Os trabalhos reunidos na coletânea retomam e desdobram esse esforço. Além disso, a lógica de organização da coletânea visa a ressaltar as possibilidades abertas para reflexão ao enfatizar a relação entre tempo e espaço, ou entre temporalização e espacialização, a partir da análise da política. Na apresentação, 
as organizadoras, depois de comentar em cada um dos trabalhos, sugerem, a partir de uma leitura transversal, perspectivas extremamente interessantes para analisar tal relação: "quanto maior a contenção da ação política em um período de tempo determinado, menos rígida sua delimitação em espaços sociais específicos [...]. De outra forma, o deslocamento, por inversão ou apropriação inusitada, de arranjos socialmente definidos e restritos a tempos e domínios que lhes são considerados consagrados parece ter a propriedade de induzir à renovação de práticas, significados e eficácia políticos” (idem, p. 18-19). Com isso, as organizadoras retomam enfoques centrais na tradição antropológica, em particular na análise de rituais, enfatizando o modo pelo qual diferentes configurações de relações são demarcadas temporal e espacialmente, apenas para serem constantemente recombinadas e transformadas de modo a gerar significados contextuais e efeitos pragmáticos.

Sem prejuízo dessas perspectivas, a riqueza de cada um dos textos permite ainda vários cruzamentos, compondo uma abordagem da política como objeto multifacetado, envolvendo diversos feixes de relação. Assim, a vontade de quantificação e o fetichismo dos números, que surgem no texto de Sprandel com um efeito despolitizador promovido por determinados agentes dos campos intelectual e político, constituindo uma percepção que obscurece qualquer pertencimento ativo dos “pobres” à comunidade política (nacional), reaparecem no texto de Borges nas equações que permitem o cálculo dos índices que redundam na possibilidade de acesso aos benefícios públicos, tendo a quantidade de tempo passado no Distrito Federal como parâmetro fundamental. Nesse caso, ainda que a quantificação seja central no controle das possibilidades de pertencimento à comunidade política, os números são reapropriados ativamente pela população, na medida em que são inseridos em tramas sociais complexas, ao surgirem como elementos na relação cotidiana entre moradores das cidades-satélite e variados funcionários do governo em contato direto com a população. Passando dos números “exatos” às “imponderáveis” emoções, no texto de Barreira a expressão das emoções dos candidatos tem um papel central na campanha política, correspondendo a uma certa expectativa social e a efeitos políticos importantes. Por isso mesmo, essa expressão é enfocada e controlada pelos “marqueteiros”, que aparentemente a incluem em seus cálculos.

A expressão das emoções é um elemento importante também nos artigos de Borges - associada por exemplo ao momento em que se constata o recebimento ou não dos lotes e apresenta-se essa constatação, de modo emocionado, à comunidade -, de Teixeira - em que deputados expressam seu descontrole emocional diante de uma agressão moral e mesmo, ainda que em menor grau, diante do que consideram manobras políticas inaceitáveis, dando aos acontecimentos uma moldura que dificulta a aplicação pura e dura do regimento - e no texto de Chaves - na carga emocional transmitida pelos testemunhos das vítimas de atos de desrespeito patrocinados por agentes do estado, no Paraná, e nos efeitos dessa expressão de emoções sobre o público presente no evento e sobre a própria validação social do mesmo. No texto de Bezerra, também, pode-se depreender que o vereador preterido pela Prefeitura na mediação das relações com o "seu” bairro exprimiu sua indignação de modo a trazer à cena claramente suas emoções, o que tem implicações para a interpretação de todos a respeito da configuração política emergente.

A relação entre eleitores, militantes ou seguidores, e políticos, por sua vez, é analisada tanto no texto de Rosato e Quirós como no texto de Bezerra. Se no caso analisado por Rosato e Quirós diferentes pressupostos quanto a esse conjunto de relações vinculam-se respectivamente a dois partidos que concorrem em uma mesma eleição, no caso analisado por Bezerra tal diferença está mais propriamente vinculada, por um lado, à proposta de orçamento participativo "em abstrato" e, por outro lado, aos comportamentos, expectativas e avaliações concretamente postos em ação ao implementar-se a proposta. Tanto no bairro de Niterói como na pequena cidade argentina em que foi analisada a atuação do Partido Justicialista, relações de amizade são centrais no estabelecimento de relações políticas. A dinâmica do Partido Justicialista prioriza como base do trabalho político visitas de caráter mais genérico, momentos de sociabilidade e não apenas transações especificamente políticas; a dinâmica da política niteroiense, por sua vez, implica que uma relação politicamente crucial entre um líder comunitário e um vereador seja descrita, em termos "nativos”, como grande amizade surgida em um jogo de futebol. Em ambos os casos, relações entre políticos, militantes e eleitores são vistas como relações “multiplex” entre pessoas. Já a análise das práticas e concepções políticas do Partido Obrero mostra-nos um modo de construção de liderança em que é fundamental não tanto a capacidade de aglutinar amigos e seguidores, mas a demonstração de conhecimento legitimado pelo partido, no sentido de um processo de apropriação de estudos e análises que permitem perceber a verdade da sociedade e das conjunturas políticas, revelando-a aos militantes. A relação com a verdade também está em jogo no Tribunal analisado por Chaves, em que a progressiva demonstração dos fatos no processo para-judicial permite perceber a verdade da política governamental, revelando-a à sociedade e com isso deslegitimando as autoridades. Nesses dois 
casos, mais do que constituir relações entre pessoas, parece estar em jogo estabelecer a mediação entre uma verdade factual e/ou analítica de valor universal e os agentes e situações. Mas a identificação da verdade não está em jogo apenas nesses casos: a expressão emocional pode revelar a verdade sobre o caráter e a natureza do candidato; as atitudes de políticos, militantes e eleitores podem permitir distinguir verdadeiras e falsas amizades entre pessoas; os números servem para delimitar os verdadeiros pobres para poder "focalizá-los" ou identificar os verdadeiros merecedores dos benefícios públicos dentre o conjunto dos moradores das cidadessatélite de Brasília.

Todos esses possíveis cruzamentos (e haveria muitos outros, dada a densidade dos textos), envolvendo política, números, emoções, amizades e verdades, poderiam por sua vez ser novamente cruzados com os eixos propostos para o livro, na perspectiva aberta pelas organizadoras. O uso dos números, a expressão de emoções, a afirmação de amizades e inimizades, a revelação de verdades, adquirem significados políticos ao relacionarem-se a tempos e espaços socialmente concebidos como "políticos". Porém, o que o conjunto dos capítulos do livro sugere não são tempos e espaços delimitados de uma vez por todas e de modo inequívoco como políticos, constituindo uma esfera política claramente discernível, passível de alguma definição formal. Eles trazem-nos múltiplas atividades, realizadas por agentes situados em configurações bastante complexas, que implicam pretensões de identificação de certos tempos e espaços como "da política" ou, ao contrário, como não sendo "da política". Tais processos de definição "em ato" do que é socialmente considerado político, por sua vez, têm uma série de implicações, já que definir como "político" aciona um conjunto de percepções, expectativas, esperanças e desconfianças bastante arraigadas nos diferentes universos sociais analisados.

O livro certamente constitui uma contribuição muito feliz no sentido de reunir trabalhos etnográficos bastante ricos e buscar possibilidades de construção conceitual a partir de tais trabalhos. Mais do que apresentar resultados fechados, o livro indica perspectivas a partir de pesquisas consistentes e convida-nos a dar continuidade a esse esforço de superar as atuais limitações do nosso aparato conceitual para pensar-se "a política”.

John Comerford (jcomerford@uol.com.br) é Doutor em Antropologia Social pela Universidade Federal do Rio de Janeiro (UFRJ) e professor do Programa de Pós-graduação em Desenvolvimento, Agricultura e Desenvolvimento da Universidade Federal Rural do Rio de Janeiro (UFRRJ).

\section{REFERÊNCIASBIBLIOGRÁFICAS}

BARREIRA, I. 2004. A expressão dos sentimentos na política. In : TEIXEIRA, C. C. \& CHAVES, C. A. (orgs.). Espaços e tempos da política. Rio de Janeiro : Relume-Dumará.

BEZERRA, M. C. 2004. Participação popular e conflitos de representação política : notas a partir de um caso de orçamento participativo. In : TEIXEIRA, C. C. \& CHAVES, C. A. (orgs.). Espaços e tempos da política. Rio de Janeiro : Relume-Dumará.

BORGES, A. M. 2004. A fórmula do tempo : notas etnográficas sobre o “tempo de Brasília”. In : TEIXEIRA, C. C. \& CHAVES, C. A. (orgs.). Espaços e tempos da política. Rio de Janeiro : Relume-Dumará.

CHAVES, C. A. 2004. Um tribunal de opinião na guerra de interpretações. In : TEIXEIRA, C. C. \& CHAVES, C. A. (orgs.). Espaços e tempos da política. Rio de Janeiro : Relume-Dumará.

ROSATO, A. \& QUIRÓS, J. 2004. De militantes y militância : el trabajo de dos partidos políticos en las elecciones legislativas de 2001 en Argentina. In : TEIXEIRA, C. C. \& CHAVES, C. A. (orgs.). Espaços e tempos da política. Rio de Janeiro : Relume-Dumará.

SPRANDEL, M. A. 2004. Da paisagem ao foco : a pobreza nos discursos sobre o Brasil. In : TEIXEIRA, C. C. \& CHAVES, C. A. (orgs.). Espaços e tempos da política. Rio de Janeiro : Relume-Dumará.

TEIXEIRA, C. C. 2004. Decoro parlamentar : entre agressões morais e indisciplinas estratégicas. In : TEIXEIRA, C. C. \& CHAVES, C. A. (orgs.). Espaços e tempos da política. Rio de Janeiro : Relume-Dumará.

TEIXEIRA, C. C. \& CHAVES, C. A. 2004. Apresentação. In : de Janeiro : Relume-Dumará. . (orgs.). Espaços e tempos da política. Rio 